Jonathan D. Burns ${ }^{1,2}$, Kristian G. Myhre ${ }^{1,3}$, Nathan J. Sims ${ }^{1}$, Daniel W. Stracener ${ }^{4}$, and Rose A. Boll ${ }^{1}$

${ }^{1}$ Nuclear Security and Isotope Technology Division, Oak Ridge National Laboratory, P.O. Box 2008, Oak Ridge, TN 37831

${ }^{2}$ Nuclear Science, Security, and Policy Institute Texas A\&M University, College Station, TX 77845, USA

${ }^{3}$ The Bredesen Center for Interdisciplinary Research and Graduate Education, University of Tennessee, Knoxville, TN 37996

\author{
${ }^{4}$ Physics Division, \\ Oak Ridge National Laboratory, P.O. Box 2008, Oak Ridge, TN 37831
}

For submission to publish in the Nuclear Instruments and Methods in Physics Research Section A as a full length article.

\section{Effects of annealing temperature on morphology and thickness of samarium electrodeposited thin films}

\begin{abstract}
This submitted manuscript has been authored by UT-Battelle, LLC, under Contract No. DE-AC0500OR22725 with the U.S. Department of Energy. The United States Government retains and the publisher, by accepting the article for publication, acknowledges that the United States Government retains a non-exclusive, paid-up, irrevocable, world-wide license to publish or reproduce the published form of this manuscript, or allow others to do so, for the United States Government purposes. The Department of Energy will provide public access to these results of federally sponsored research in accordance with the DOE Public Access Plan (http://energy.gov/downloads/doe-public-access-plan).
\end{abstract}

Research sponsored by the U.S. Department of Energy, Office of Nuclear Physics, Isotope Development and Production for Research and Applications Program. 


\section{Effects of annealing temperature on morphology and thickness of}

48 samarium electrodeposited thin films

50 Jonathan D. Burns, Kristian G. Myhre, Nathan J. Sims, Daniel W. Stracener, and

$51 \quad$ Rose A. Boll

52

53 Abstract

54 Electroplated depositions of Sm were prepared using a vertical well-type electrodeposition unit

55 with an aqueous ammonium acetate electrolyte system, with an average deposition yield just

56 over $87 \%$. The depositions were analyzed for morphology and thickness by scanning electron

57 microscopy (SEM) and chemical composition by energy dispersion X-ray spectroscopy (EDS)

58 and X-ray photoelectron spectroscopy (XPS) before and after firing. The depositions were fired

59 at 125 to $700{ }^{\circ} \mathrm{C}$, while varying the heating rate from 0.5 to $10^{\circ} \mathrm{C} / \mathrm{min}$ in either an oxidizing or

60 reducing atmosphere. A heating rate of $10^{\circ} \mathrm{C} / \mathrm{min}$ was slow enough to prevent disruption of the

61 deposition morphology during firing. A gas sweep enhanced the removal of any organic

62 substituents, with an oxidizing environment being more advantageous than a reducing

63 environment.

64

\section{1. Introductions}

66 Actinide thin-films have gained significant attention over the last several decades for a myriad of

67 applications including accelerator bombardments [1-3], $\alpha-$-spectroscopy [4,5], and fission

68 fragment sources [6-9]. The Californium Rare Isotope Breeder Upgrade (CARIBU) at Argonne 
69 National Laboratory's Argonne Tandem Linear Accelerator System (ATLAS) has generated the

70 need to produce high-activity, thin-film fission fragment sources using ${ }^{252} \mathrm{Cf}$. The Radiochemical

71 Engineering Development Center (REDC) at the Oak Ridge National Laboratory (ORNL) is one

72 of the few producers of ${ }^{252} \mathrm{Cf}$ in the world and is responsible for every aspect of production,

73 purification, and source fabrication. [10,11] Recently, the largest electrodeposition of ${ }^{252} \mathrm{Cf}$ ever

74 prepared was produced at the REDC, measuring $6.3 \pm 0.4 \mathrm{GBq}(1.7 \pm 0.1 \mathrm{Ci}){ }^{252} \mathrm{Cf}$. [8,9]

75 However, despite the ${ }^{252} \mathrm{Cf}$ material being extensively purified, the source was thicker than

76 desired for the application, reducing the overall fission fragment yield. This is believed to

77 originate from the electrodeposition technique where the organic substituents from the

78 ammonium acetate electrolyte solution are deposited along with the ${ }^{252} \mathrm{Cf}$.

80 This work focuses on the effort to better understand the electroplating of lanthanides and

81 actinides by using natural $\mathrm{Sm}$ as a representative lanthanide and a surrogate for $\mathrm{Cf}$. The effect of

82 annealing temperature on the deposited film morphology, thickness, and chemical composition

83 will be discussed, with special attention on the differences observed from firing under oxidizing

84 or reducing atmospheres.

\section{2. Experimental}

\section{$87 \quad 2.1$ Materials}

89 Nitric acid (Optima, $\left.\mathrm{HNO}_{3}\right)$ and ammonium acetate $\left(98.8 \%, \mathrm{NH}_{4} \mathrm{Ac}\right)$ were purchased from

90 Thermo Fisher Scientific Inc.; anhydrous samarium chloride (99.9\%, ultra-dry $\left.\mathrm{SmCl}_{3}\right)$ was

91 purchased from Alfa Aesar; ammonium hydroxide (ACS Grade, $\mathrm{NH}_{4} \mathrm{OH}$ ) was purchased from 
92 Sigma-Aldrich; hydrochloric acid (OmniTrace Ultra, $\mathrm{HCl})$ was purchased from EMD Chemicals

93 Inc.; and distilled deionized (ddi) $\mathrm{H}_{2} \mathrm{O}$ was obtained from a Millipore Milli-Q ${ }^{\circledR}$ Academic

94 Ultrapure Water Purification System with a Quantum ${ }^{\circledR}$ EX Ultrapure Organex Cartridge filter

95 operated at $18.2 \mathrm{M} \Omega \mathrm{cm}$ at $25^{\circ} \mathrm{C}$.

\section{$97 \quad 2.2$ Electrodeposition}

98 The electrodeposition unit had a well-type configuration and has been described in detail

99 elsewhere. [8] A short description is provided here: The unit comprised a copper cathode that

100 housed an embedded stainless steel (SS) plate as the deposition substrate with a deposition area

101 of $5.6 \mathrm{~cm}^{2}$. The solution well was machined out of polyether ether ketone (PEEK). A silicon

102 gasket was used to complete the seal between the well and the substrate. The anode was a

103 platinum plate with slits in it to prevent gas from accumulating between the electrodes. The

104 anode was suspended in the well so that a distance of $1 \mathrm{~cm}$ was maintained between the anode

105 and the deposition surface (cathode). The entire unit was designed and fabricated at ORNL.

106 Electrodepositions were carried out using an Agilent E3616A 0-25 V, 0.0-1.7 A DC Power

107 Supply in the constant current mode, allowing the potential to vary.

108

109 Prior to each deposition run, the unit was subsequently washed with $1 M \mathrm{HNO}_{3}$, ethanol, and ddi

$110 \mathrm{H}_{2} \mathrm{O}$. It was then assembled and leak tested with $0.35 \mathrm{M} \mathrm{NH}_{4} \mathrm{Ac}$ for a minimum of $12 \mathrm{~h}$. Upon

111 passing the leak test, the unit was set up for the electrodeposition run. Each run consisted of

112 adding a $200 \mu \mathrm{L}$ aliquot of $100 \mathrm{mM} \mathrm{SmCl}{ }_{3} 0.05 \mathrm{M} \mathrm{HCl}\left(\sim 3.0 \mathrm{mg}\right.$ of $\left.\mathrm{Sm}^{3+}\right)$ to the deposition unit,

113 which contained $10.3 \mathrm{~mL}$ of $0.35 \mathrm{M} \mathrm{NH}_{4} \mathrm{Ac}$, making the final electrolyte volume $10.5 \mathrm{~mL}$. The

114 anode was then submersed in the electrolyte solution; both electrodes were then connected to the 
115 power source and energized. The current was increased slowly over the first 5 min until it

116 reached the desired setting of $0.700 \mathrm{~A}$, at which point the current was held constant for the

117 duration of deposition, which was $4 \mathrm{~h}$. This current was selected to mimic the current density of

$118125 \mathrm{~mA} / \mathrm{cm}^{2}$ used with previous ${ }^{252} \mathrm{Cf}$ depositions. [8,9] At the end of the deposition, $1 \mathrm{~mL}$ of

119 concentrated $\mathrm{NH}_{4} \mathrm{OH}$ was added prior to de-energizing the power source to prevent the deposited

120 material from dissolving once the potential was removed. The electrolyte solution was then

121 collected, sampled, and analyzed using neutron activation analysis (NAA). The overall error in

122 deposition yield was calculated by propagating the statistical error from NAA analysis and the

123 systematic error from the experiments using standard methods.

124

\section{$125 \quad 2.3$ Deposition Firing}

126 The depositions were heated using a Thermo Scientific Lindberg/Blue M Mini-Mite Tube

127 Furnace TF55035A-1 with a 12 in. heating zone operating from $100-1100{ }^{\circ} \mathrm{C}$, controlled by an

128 Omega Engineering, Inc. digital, multi-segment programmable controller. Several firing patterns

129 were investigated including ambient to $125^{\circ} \mathrm{C}$ at $0.5^{\circ} \mathrm{C} / \mathrm{min}$, holding for $60 \mathrm{~min}$; and ambient to

$130700{ }^{\circ} \mathrm{C}$ at $0.5^{\circ} \mathrm{C} / \mathrm{min}$, holding for $60 \mathrm{~min}$. These firing patterns were conducted under an air

131 atmosphere with no gas sweep and also a $96 \% \mathrm{He} 4 \% \mathrm{H}_{2}$ mixture with a gas sweep of roughly

$1322 \mathrm{psig}$ in either a quartz or mullite tube. A firing pattern of ambient to $125^{\circ} \mathrm{C}$ at $0.5^{\circ} \mathrm{C} / \mathrm{min}$,

133 holding for $60 \mathrm{~min}$, and then continuing up to $700^{\circ} \mathrm{C}$ at $0.5^{\circ} \mathrm{C} / \mathrm{min}$, holding for $60 \mathrm{~min}$, was used

134 under an air atmosphere with no gas sweep. Other firing patterns from ambient to $125^{\circ} \mathrm{C}$,

135 holding for $60 \mathrm{~min}$, and continuing up to $700{ }^{\circ} \mathrm{C}$ and holding for $60 \mathrm{~min}$, with heating rates of 2

136 and $10{ }^{\circ} \mathrm{C} / \mathrm{min}$ were performed under either an air atmosphere with and without a gas sweep or

$13796 \% \mathrm{He} 4 \% \mathrm{H}_{2}$ mixture with a gas sweep of roughly 2 psig in an alumina tube. 
1392.4 Scanning Electron Microscopy (SEM), Energy Dispersive X-ray Spectroscopy

140 (EDS), and X-ray Photoelectron Spectroscopy (XPS)

141 Scanning electron microscopy (SEM) along with energy dispersive X-ray spectroscopy (EDS)

142 was performed to study the morphology, thickness, and qualitative chemical analysis using a

143 Hitachi S-3400N Scanning Electron Microscope coupled with a Hitachi EDAX 3400 EDX

144 detector housed at the High Temperature Materials Laboratory (HTML) at ORNL. The SEM

145 electron beam was operated at an accelerating voltage of $10 \mathrm{kV}$, and the images recorded the

146 back-scattered electron (BSE) detector signal. The EDS data were analyzed for relative chemical

147 composition using the EDAX Genesis software. Images were taken of the deposition substrate

148 with the beam perpendicular to the surface for a top-down view and with the substrate tilted $90^{\circ}$

149 to view the profile of the deposits.

151 The particle size distributions were determined using ImageJ version $1.50 \mathrm{~b}$ software. The area of 152 each deposition fragment was obtained, and then a gross estimation of the size of each fragment 153 was approximated by assuming each fragment to be circular and calculating the diameter of each 154 circular fragment. Fragments with an area smaller than $20 \mu \mathrm{m}^{2}$ were removed from the analysis. 155 This simplification allowed for semi-quantitative analysis of the change in size of the fragments 156 before and after firing the depositions.

158 X-ray photoelectron spectroscopy (XPS) was performed to obtain more detailed analysis of the 159 composition and binding of the depositions using a Thermo Scientific K-Alpha XPS with a 160 double-focusing hemispherical analyzer and a position-sensitive detector with 128 detector 
161 elements. The spectrometer was operated in the constant analyzer energy mode, with a $0.25 \mathrm{~m}$

162 Rowland circle monochromator with a micro-focused X-ray source extraction source window

163 comprised of a water-cooled aluminum-coated anode at an energy of $1486.68 \mathrm{eV}$ and strength of

$16472 \mathrm{~W}$. The beam size was $400 \times 400 \mu \mathrm{m}$, and the analyzer width was $60 \times 60 \mathrm{~mm}$ operating in a

165 multichannel direct signal mode. The samples were first interrogated with a large survey energy

166 scan to determine the elements present, followed by narrow-region scans to probe the core levels

167 in the elements of interest to better determine type of bonding and oxidation of each element.

168 The samples were then etched using an argon ion beam, and the survey and narrow region scans

169 were repeated. This was performed on a deposition prior to firing and on a deposition fired with

170 the firing pattern starting from ambient to $125^{\circ} \mathrm{C}$, holding for $60 \mathrm{~min}$, and continuing up to

$171700{ }^{\circ} \mathrm{C}$ and holding for $60 \mathrm{~min}$, with heating rates of $2{ }^{\circ} \mathrm{C} / \mathrm{min}$ under an air atmosphere with a gas

172 sweep of roughly 2 psig, deposition 3.

173

$174 \quad 2.5$ Deposition Yield by Neutron Activation Analysis (NAA)

175 NAA was performed at the High Flux Isotope Reactor (HFIR) in the PT-1 pneumatic tube station 176 to determine the electrodeposition yields. Irradiations were performed on the stock Sm solution 177 and samples of the post-deposition electrolyte solutions for either 20 or $300 \mathrm{~s}$, depending on the 178 expected amount of $\mathrm{Sm}$ in each sample. The samples were prepared by taking an aliquot (10 or

$179100 \mu \mathrm{L}$, respectively) to dryness in a high-density polyethylene (HDPE) insert which was sealed 180 and placed into an HDPE pneumatic tube capsule for irradiation. The irradiated samples were 181 analyzed by gamma $(\gamma)$-ray spectroscopy using a Canberra N-type high-purity germanium 182 detector (HPGe) with $44 \%$ relative efficiency (endcap diameter $=2.5$ in.) and a Lynx $32 \mathrm{k}-$ 183 channel MCA running Genie 2000 gamma spectroscopy software. The detector has an energy 
184 resolution of approximately $2 \mathrm{keV}$ at $1332 \mathrm{keV}$. Relevant nuclear data were obtained from

185 Browne and Firestone. [12] The HPGe detector was calibrated using a multi-isotopic standard.

186 The activated ${ }^{153} \mathrm{Sm}\left(\mathrm{t}_{1 / 2}=46.284 \mathrm{~h}\right)$ was tracked by the $103 \mathrm{keV} \gamma$-ray. The deposition yields

187 were determined by comparing the $[\mathrm{Sm}]$ in the electrolyte solution before and after deposition,

188 taking into account decay time, irradiation time differences, and dilutions.

\section{Results and Discussion}

191 The deposition yield from all 16 depositions was very consistent and showed very high

192 deposition efficiency, averaging just over 87\% (Table 1). Some variation in yield is not

193 uncommon for electroplated depositions. [13] The results repeated here display higher efficiency

194 and better consistency than previously reported for electrodepositions of $\mathrm{Sm}$ from an $\mathrm{NH}_{4} \mathrm{Ac}$

195 electrolyte system. This high efficiency is believed to be a result of a better electrodeposition unit

196 design, which allows for a constant, uniform electric field across the entire surface of the SS

197 deposition substrate by holding the flat anode perpendicular to the surface at a distance of $1 \mathrm{~cm}$.

198 Table 1

199 Deposition yield for the sixteen depositions

\begin{tabular}{cccc}
\hline ID & $\begin{array}{c}\text { Deposition } \\
\text { Yield (\%) }\end{array}$ & ID & $\begin{array}{c}\text { Deposition } \\
\text { Yield (\%) }\end{array}$ \\
\hline 1 & $99.2 \pm 2.2$ & 9 & $88.2 \pm 1.6$ \\
2 & $87.8 \pm 2.1$ & 10 & $91.6 \pm 1.5$ \\
3 & $92.6 \pm 2.1$ & 11 & $70.7 \pm 1.6$ \\
4 & $80.1 \pm 2.1$ & 12 & $91.7 \pm 1.5$ \\
5 & $85.0 \pm 2.1$ & 13 & $93.9 \pm 1.6$ \\
6 & $96.3 \pm 1.5$ & 14 & $94.4 \pm 1.6$ \\
7 & $77.6 \pm 1.6$ & 15 & $92.4 \pm 1.6$ \\
8 & $91.3 \pm 1.5$ & 16 & $64.3 \pm 1.5$ \\
\hline
\end{tabular}

201 The depositions, before and after firing, were then analyzed for morphology and thickness with

202 an electron microscope using a BSE detector. Three sets of samples were analyzed: samples fired

203 to $125^{\circ} \mathrm{C}$ and held for $60 \mathrm{~min}$ (Tables 2 and 3); samples fired to $700{ }^{\circ} \mathrm{C}$ and held for $60 \mathrm{~min}$ 
204 (Tables 4 and 5); and samples fired to $125^{\circ} \mathrm{C}$, held for $60 \mathrm{~min}$, increased to $700{ }^{\circ} \mathrm{C}$, and held for

$20560 \mathrm{~min}$ (Table 6,7 , and 8 ). In all three cases, a ramp rate of $0.5^{\circ} \mathrm{C} / \mathrm{min}$ was used. Additionally,

206 the third case was repeated with alternate ramp rates of $2{ }^{\circ} \mathrm{C} / \mathrm{min}$ or $10^{\circ} \mathrm{C} / \mathrm{min}$. Each firing

207 process was run under either an oxidizing atmosphere (air) or a reducing atmosphere $(96 \% \mathrm{He}$

$2084 \% \mathrm{H}_{2}$ mixture). A general description of the unfired depositions will be given followed by the

209 effects of firing the depositions at the various temperatures and ramping rates.

211 Fig. 1 shows a typical BSE image of the depositions prior to firing. As shown in the figure, the

212 surface is not smooth and has large defects. Severe cracking is seen and is a result of the so-

213 called "mud-caking" effect, which is observed commonly in electroplating techniques with

214 materials assumed to have a "columnar" microstructure. [14,15] The insert in Fig. 1 shows an

215 edge view of a deposition, with a fragment that has pronounced curling of the edges, very much

216 in line with mud-caking. Due to the large cracking of the deposition, a significant portion of the

217 SS substrate is exposed, which can be clearly identified by the parallel grooves, resulting from

218 the machining of the substrate. The surface of the fragments is irregular and can be generally

219 characterized as rough with smooth patches. According to EDS analysis, there is no

220 distinguishable difference in chemical composition of the rough and smooth patches.

222 Since the surface is not completely covered by the deposition, meaningful results from large-area

223 EDS measurements could not be obtained. Instead, given that the fragments are similar in

224 composition, several spots on different fragments were analyzed, and an average was calculated

225 for the chemical composition of the deposition as a whole. In all cases, a small amount of Pt is

226 observed, indicating slight dissolution and plating of the Pt anode, which is not surprising. There 
was a significant amount of carbon in all the depositions, 44-57 atom \%. The carbon is believed

249 to originate from the acetate in the electrolyte. It is unclear at this point what the form of the

250 carbon is, but a couple suggestions are offered here. First, the acetate could be coordinating to

251 the surface of the samarium electroplated deposition and terminating the deposited material.

252 Second, the acetate could be incorporated within the deposition. In either case, the acetate serves

253 as a diluent, reducing the overall Sm concentration in the fragments, while increasing the

254 thickness of the fragments. Neither of these effects is desirable for making a thin film of Sm.

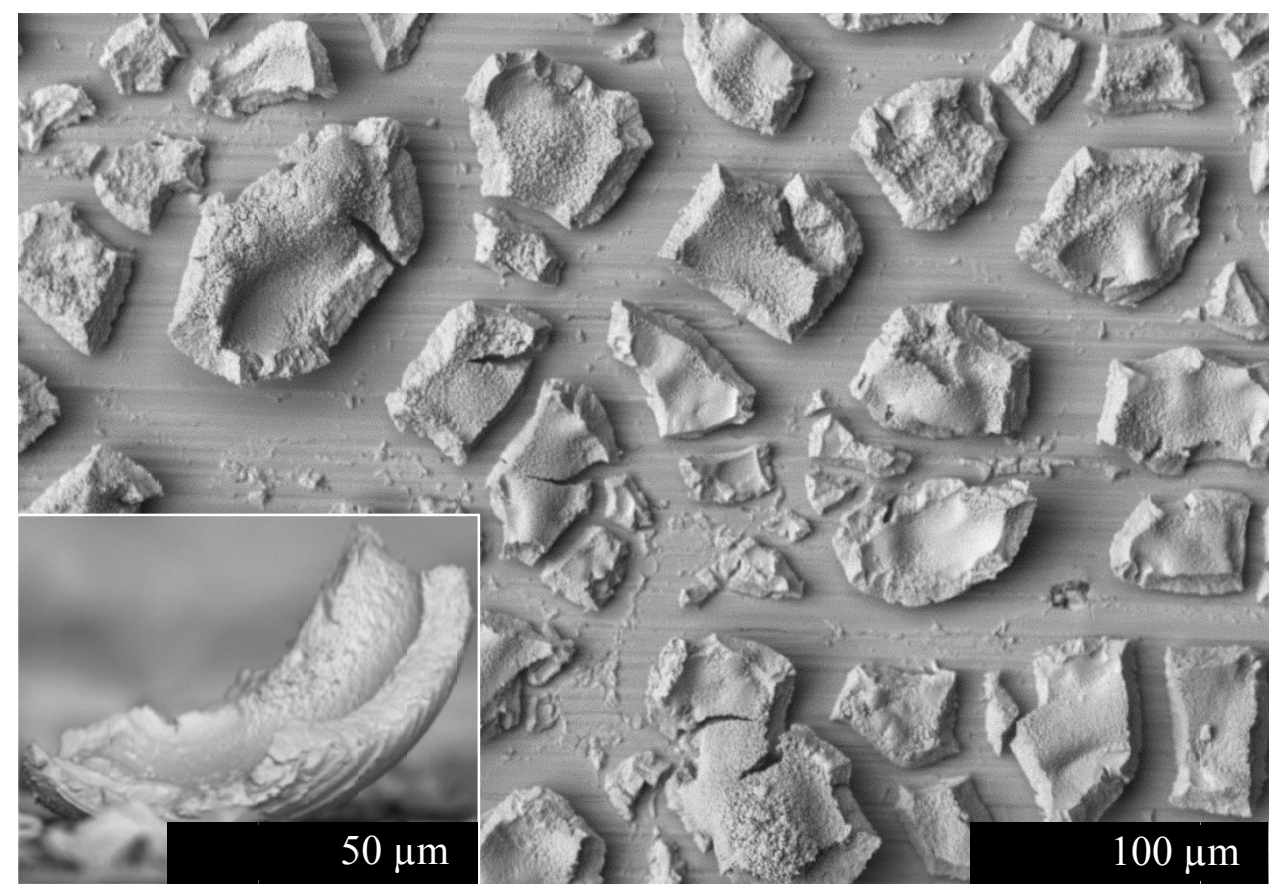

Fig. 1. BSE image of a typical prefired deposition with the so-called "mud-caking" features. Insert shows an edge view of a curling fragment.

Depositions 1 and 2 were fired in air, and depositions 3 and 4 were fired in a 96\% $\mathrm{He} 4 \% \mathrm{H}_{2}$

256 mixture to $125^{\circ} \mathrm{C}$ at a ramp rate of $0.5^{\circ} \mathrm{C} / \mathrm{min}$ (the results of the firings are displayed in Tables 2

257 and 3, respectively). There appears to be a slight reduction in the $\mathrm{C}$ content after firing; however,

258 due to the inherent variability of EDS measurements, especially for light elements such as C, it is

259 difficult to say definitively whether any change had taken place, either chemically or physically.

260 It can be seen in Fig. 2 that the surface characteristics and morphology are very similar to what 
243 was observed prior to firing. This is expected, as at this low temperature, only water will be

244 driven from the deposition. As long as the ramp rate is slow, in this case $0.5^{\circ} \mathrm{C} / \mathrm{min}$, the removal

245 of any moisture should be a gentle process and should not cause any violent process to occur and

246 damage the material as it leaves. If only water is being removed, there is expected to be very

247 little reduction in fragment thickness, which is what was observed for the firings in both

248 oxidizing and reducing atmospheres.

249 Table 2

250 Deposition thickness, size, and composition before and after firing to $125^{\circ} \mathrm{C}$ in air without a gas sweep.

\begin{tabular}{cccccccccc}
\hline ID & & $\begin{array}{c}\text { Thickness } \\
(\mu \mathrm{m})\end{array}$ & $\begin{array}{c}\text { Area } \\
\left(\mu \mathrm{m}^{2}\right)\end{array}$ & $\begin{array}{c}\text { Diameter }(\mu \mathrm{m}) \\
\text { Range }\end{array}$ & $\begin{array}{c}\text { \% } \mathrm{Sm} \\
\text { (atom) }\end{array}$ & $\begin{array}{c}\% \mathrm{O} \\
\text { (atom) }\end{array}$ & $\begin{array}{c}\% \mathrm{C} \\
\text { (atom) }\end{array}$ & $\begin{array}{c}\% \mathrm{Pt} \\
(\text { atom })\end{array}$ \\
\hline \multirow{2}{*}{1} & Unfired & $4-8$ & $33-2240$ & $7-53$ & $30 \pm 11$ & 13 & 31 & 54 & 2 \\
& Fired & $5-10$ & $32-2256$ & $6-54$ & $27 \pm 14$ & 15 & 38 & 46 & 2 \\
2 & Unfired & $4-8$ & $26-2505$ & $6-56$ & $26 \pm 14$ & 16 & 38 & 44 & 2 \\
& Fired & $4-8$ & $29-4810$ & $6-78$ & $31 \pm 18$ & 15 & 39 & 44 & 2 \\
\hline
\end{tabular}

Table 3

253 Deposition thickness, size, and composition before and after firing to $125^{\circ} \mathrm{C}$ in a $96 \% \mathrm{He} 4 \% \mathrm{H}_{2}$ gas sweep.

\begin{tabular}{|c|c|c|c|c|c|c|c|c|c|}
\hline \multirow{2}{*}{ ID } & & \multirow{2}{*}{$\begin{array}{c}\text { Thickness } \\
(\mu \mathrm{m})\end{array}$} & \multirow{2}{*}{$\begin{array}{l}\text { Area } \\
\left(\mu \mathrm{m}^{2}\right)\end{array}$} & \multicolumn{2}{|c|}{ Diameter $(\mu \mathrm{m})$} & \multirow{2}{*}{$\begin{array}{l}\% \mathrm{Sm} \\
\text { (atom) }\end{array}$} & \multirow{2}{*}{$\begin{array}{c}\% \mathrm{O} \\
\text { (atom) }\end{array}$} & \multirow{2}{*}{$\begin{array}{c}\% \mathrm{C} \\
\text { (atom) }\end{array}$} & \multirow{2}{*}{$\begin{array}{c}\% \mathrm{Pt} \\
\text { (atom) }\end{array}$} \\
\hline & & & & Range & Mean & & & & \\
\hline \multirow[t]{2}{*}{3} & Unfired & $3-6$ & $22-5721$ & $5-85$ & $35 \pm 17$ & 15 & 31 & 52 & 2 \\
\hline & Fired & $3-9$ & $24-7666$ & $5-99$ & $34 \pm 21$ & 15 & 38 & 44 & 2 \\
\hline \multirow[t]{2}{*}{4} & Unfired & $4-9$ & $27-1688$ & $6-46$ & $22 \pm 11$ & 13 & 32 & 53 & 2 \\
\hline & Fired & $4-7$ & $21-1052$ & $5-37$ & $19 \pm 9$ & 15 & 38 & 45 & 2 \\
\hline
\end{tabular}




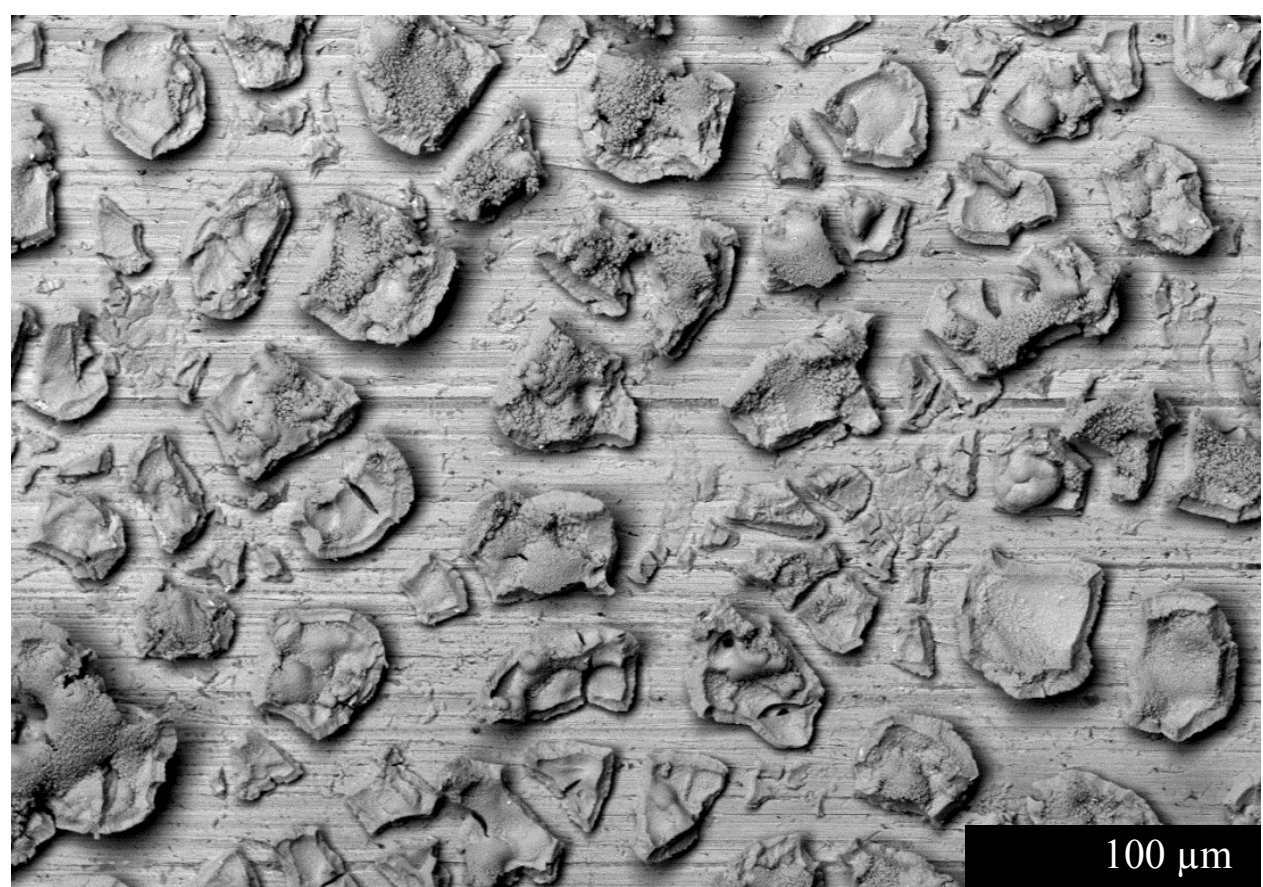

Fig. 2. Deposition after being fired to $125^{\circ} \mathrm{C}$ and held for $60 \mathrm{~min}$.

257 Increasing the firing temperature to $700{ }^{\circ} \mathrm{C}$ in both an oxidizing and reducing atmosphere had a

258 significant impact on the depositions. In Fig. 3 it can be seen that substantial shrinkage of the

259 fragments occurred with an average reduction in diameter of 33\% in depositions 5-8 (Tables 4

260 and 5). A much larger fraction of the SS substrate is exposed, with a residue line where it appears

261 the original border of the fragments were prior to shrinking. The fragments are also much

262 brighter relative to the substrate in the BSE image, indicating an increase in electron density,

263 which can be thought of as an increase of average atomic mass of the fragments. In other words,

264 the density of Sm increased. This is clearly shown in the EDS data; the atom \% of Sm increased

265 by almost a factor of 2 in the oxidizing atmosphere and 2.6 in the reducing atmosphere, while

266 that of $\mathrm{C}$ was cut almost in half in the oxidizing atmosphere and only by $30 \%$ in the reducing

267 atmosphere. Once again, the EDS data are not a precise quantitative measurement, especially for

268 light elements like C, but they do indicate a shift in the composition of the material, indicating

269 that the $\mathrm{C}$ is being removed from the fragments by the increase in firing temperature. The

270 morphology of the fragments was changed from being mostly rough to mostly smooth. This may 
271 indicate it was the $\mathrm{C}$, presumably in the form of acetate that contributed to the roughness of the

272 surface. Despite there being a considerable difference in size of the diameter of the fragments,

273 the reduction in thickness was not as striking. In fact, it appeared that instead of the deposition

274 becoming thinner with the removal of $\mathrm{C}$, as anticipated, the thickness stayed relatively constant,

275 but the aspect ratio shrunk. That is to say, the change in size, as a result of loss in mass from C,

276 maintained the thickness and reduced the area of the particle.

277

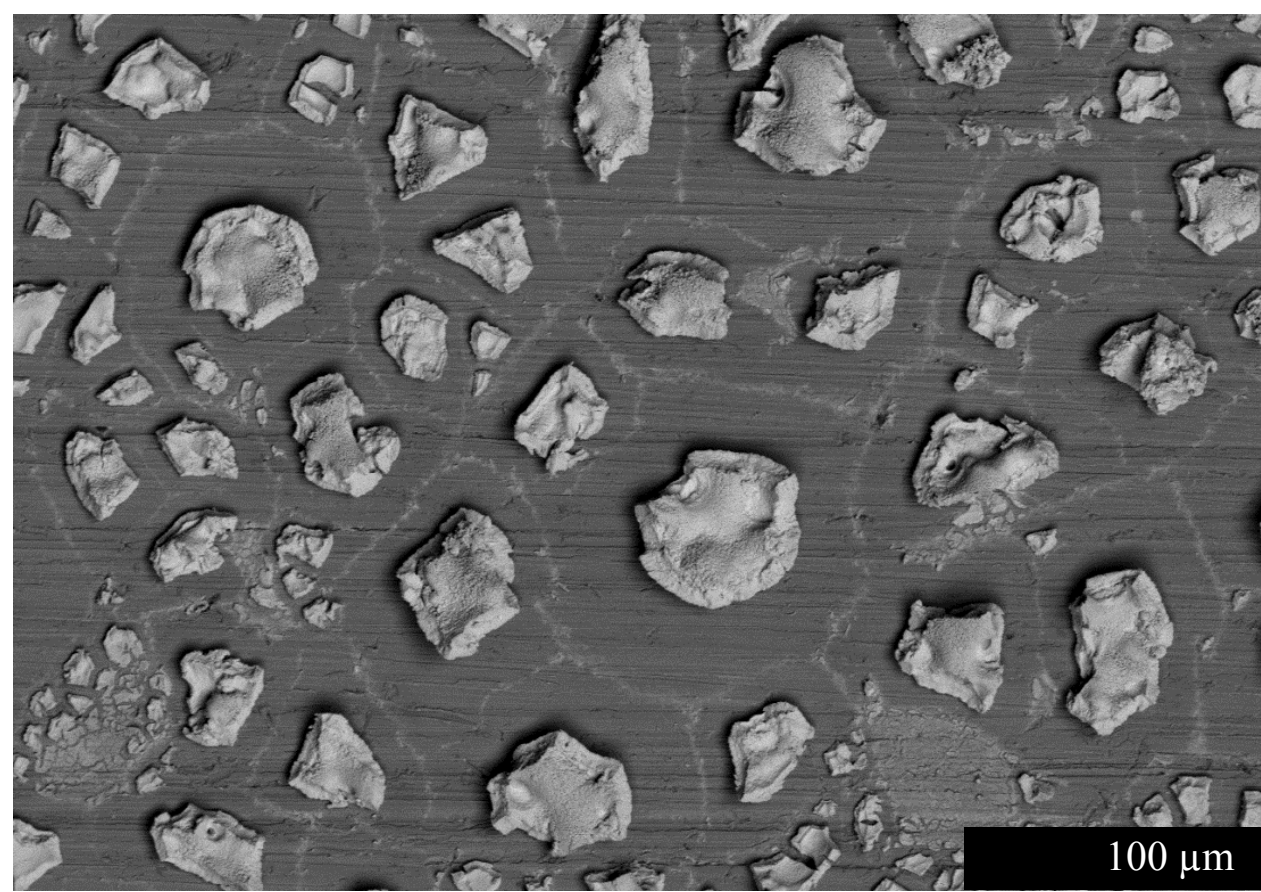

279 Fig. 3. Deposition after being fired to $700{ }^{\circ} \mathrm{C}$ and held for $60 \mathrm{~min}$.

$281 \quad$ Table 4

282 Deposition thickness, size, and composition before and after firing to $700{ }^{\circ} \mathrm{C}$ in air without a gas sweep.

\begin{tabular}{|c|c|c|c|c|c|c|c|c|c|}
\hline \multirow{2}{*}{ ID } & & \multirow{2}{*}{$\begin{array}{c}\text { Thickness } \\
(\mu \mathrm{m})\end{array}$} & \multirow{2}{*}{$\begin{array}{l}\text { Area } \\
\left(\mu \mathrm{m}^{2}\right)\end{array}$} & \multicolumn{2}{|c|}{ Diameter $(\mu \mathrm{m})$} & \multirow{2}{*}{$\begin{array}{c}\% \mathrm{Sm} \\
\text { (atom) }\end{array}$} & \multirow{2}{*}{$\begin{array}{c}\% \mathrm{O} \\
\text { (atom) }\end{array}$} & \multirow{2}{*}{$\begin{array}{c}\% \mathrm{C} \\
\text { (atom) }\end{array}$} & \multirow{2}{*}{$\begin{array}{c}\% \mathrm{Pt} \\
\text { (atom) }\end{array}$} \\
\hline & & & & Range & Mean & & & & \\
\hline \multirow[t]{2}{*}{5} & Unfired & $4-10$ & $31-2104$ & $6-52$ & $24 \pm 12$ & 15 & 39 & 44 & 1 \\
\hline & Fired & $3-6$ & $21-3337$ & $5-65$ & $16 \pm 11$ & 31 & 40 & 24 & 5 \\
\hline \multirow[t]{2}{*}{6} & Unfired & $4-7$ & $21-3262$ & $5-64$ & $24 \pm 14$ & 15 & 39 & 44 & 2 \\
\hline & Fired & $2-6$ & $21-2547$ & $5-57$ & $17 \pm 13$ & 27 & 42 & 26 & 4 \\
\hline
\end{tabular}


Table 5

285 Deposition thickness, size, and composition before and after firing to $700{ }^{\circ} \mathrm{C}$ in a $96 \% \mathrm{He} 4 \% \mathrm{H}_{2}$ gas sweep.

\begin{tabular}{|c|c|c|c|c|c|c|c|c|c|}
\hline \multirow{2}{*}{ ID } & & \multirow{2}{*}{$\begin{array}{c}\text { Thickness } \\
(\mu \mathrm{m})\end{array}$} & \multirow{2}{*}{$\begin{array}{l}\text { Area } \\
\left(\mu \mathrm{m}^{2}\right)\end{array}$} & \multicolumn{2}{|c|}{ Diameter $(\mu \mathrm{m})$} & \multirow{2}{*}{$\begin{array}{l}\% \mathrm{Sm} \\
\text { (atom) }\end{array}$} & \multirow{2}{*}{$\begin{array}{c}\% \mathrm{O} \\
\text { (atom) }\end{array}$} & \multirow{2}{*}{$\begin{array}{c}\% \mathrm{C} \\
\text { (atom) }\end{array}$} & \multirow{2}{*}{$\begin{array}{c}\% \mathrm{Pt} \\
\text { (atom) }\end{array}$} \\
\hline & & & & Range & Mean & & & & \\
\hline \multirow[t]{2}{*}{7} & Unfired & $5-10$ & 21-3379 & $5-66$ & $21 \pm 12$ & 7 & 36 & 57 & $\leq 1$ \\
\hline & Fired & $3-7$ & $21-2467$ & $5-56$ & $18 \pm 12$ & 18 & 41 & 40 & 2 \\
\hline \multirow[t]{2}{*}{8} & Unfired & $4-7$ & $26-4188$ & $6-73$ & $36 \pm 19$ & 7 & 35 & 57 & $\leq 1$ \\
\hline & Fired & $2-6$ & $21-2007$ & $5-51$ & $17 \pm 12$ & 18 & 41 & 39 & 1 \\
\hline
\end{tabular}

A firing program was then investigated where the temperature was held at $125^{\circ} \mathrm{C}$ for 60 min

before continuing on to $700{ }^{\circ} \mathrm{C}$ and holding to identify the effects on morphology and thickness.

As shown in Table 6 , two heating rates were studied, the $0.5^{\circ} \mathrm{C} / \mathrm{min}$ as before, depositions $9-10$, and $2{ }^{\circ} \mathrm{C} / \mathrm{min}$, depositions $11-12$. The rate of $0.5^{\circ} \mathrm{C} / \mathrm{min}$ showed results similar to those of the

291 firing that went straight to $700^{\circ} \mathrm{C}$ without holding at $125^{\circ} \mathrm{C}$. The morphology of the two-step

292 firing had no observable differences from the one-step firing when viewed by the electron

293 microscope. It appears any bound water was removed at a moderately slow rate without any

294 violent releases to disrupt the surface of the material. This means that at the rate of $0.5^{\circ} \mathrm{C} / \mathrm{min}$

295 there is no benefit to holding the temperature at $125^{\circ} \mathrm{C}$ for the purpose of driving off the

296 moisture.

298 Surprisingly, the faster heating rate of $2{ }^{\circ} \mathrm{C} / \mathrm{min}$ appeared to increase the relative amount of $\mathrm{Sm}$

299 observed by EDX (Table 6) by slightly reducing the overall C content and significantly reducing

300 the $\mathrm{O}$ content compared to the slower heating rate of $0.5^{\circ} \mathrm{C} / \mathrm{min}$. For these experiments, the

301 furnace was open on either end of the tube, with no gas sweep. It is believed that at some

302 temperature the heating zone will create a convection current that will not allow air to flow back

303 into the area where the deposition is located, so that the region in the heating zone could become

304 depleted in $\mathrm{O}_{2}$. If this were to take place, firing at a slower heating rate would spend more time at

305 this depleted atmosphere, and firing at a faster ramp rate would spend less time in this depleted 
atmosphere and potentially make it to a higher temperature, driving off more of the organic

307 substituents.

308 Table 6

309 Deposition thickness, size, and composition before and after firing to $125^{\circ} \mathrm{C}$, holding, and continuing up to $700{ }^{\circ} \mathrm{C}$ and holding in 310 air without a gas sweep.

\begin{tabular}{|c|c|c|c|c|c|c|c|c|c|c|}
\hline \multirow{2}{*}{ ID } & & \multirow{2}{*}{$\begin{array}{l}\text { Ramp Rate } \\
\left({ }^{\circ} \mathrm{C} / \mathrm{min}\right)\end{array}$} & \multirow{2}{*}{$\begin{array}{l}\text { Thickness } \\
(\mu \mathrm{m})\end{array}$} & \multirow{2}{*}{$\begin{array}{l}\text { Area } \\
\left(\mu \mathrm{m}^{2}\right)\end{array}$} & \multicolumn{2}{|c|}{ Diameter $(\mu \mathrm{m})$} & \multirow{2}{*}{$\begin{array}{l}\% \mathrm{Sm} \\
\text { (atom) }\end{array}$} & \multirow{2}{*}{$\begin{array}{c}\% \mathrm{O} \\
\text { (atom) }\end{array}$} & \multirow{2}{*}{$\begin{array}{c}\% \mathrm{C} \\
\text { (atom) }\end{array}$} & \multirow{2}{*}{$\begin{array}{c}\% \mathrm{Pt} \\
\text { (atom) }\end{array}$} \\
\hline & & & & & Range & Mean & & & & \\
\hline \multirow[t]{2}{*}{9} & Unfired & 0.5 & $5-10$ & $22-3976$ & $5-71$ & $26 \pm 14$ & 8 & 36 & 56 & 1 \\
\hline & Fired & & $4-8$ & $21-2362$ & $5-55$ & $14 \pm 10$ & 17 & 41 & 40 & 2 \\
\hline \multirow[t]{2}{*}{10} & Unfired & 0.5 & $4-9$ & $21-8047$ & $5-101$ & $26 \pm 18$ & 8 & 36 & 56 & 1 \\
\hline & Fired & & $3-9$ & $21-3015$ & $5-62$ & $18 \pm 14$ & 17 & 41 & 39 & 2 \\
\hline \multirow[t]{2}{*}{11} & Unfired & 2 & $4-11$ & $22-8132$ & $5-102$ & $22 \pm 14$ & 7 & 35 & 57 & $\leq 1$ \\
\hline & Fired & & $3-7$ & $20-1971$ & $5-50$ & $16 \pm 9$ & 27 & 32 & 37 & 4 \\
\hline \multirow[t]{2}{*}{12} & Unfired & 2 & $5-9$ & $22-2572$ & $5-57$ & $25 \pm 12$ & 7 & 35 & 57 & $\leq 1$ \\
\hline & Fired & & $3-8$ & $20-2022$ & $5-51$ & $15 \pm 11$ & 27 & 33 & 35 & 4 \\
\hline
\end{tabular}

311

312 To test if the heating zone was becoming depleted, the firing with a heating rate of $2{ }^{\circ} \mathrm{C} / \mathrm{min}$ was

313 repeated with depositions 1 and 3 in an air atmosphere with a gas sweep to continuously push

314 fresh air over the depositions throughout the firing. At the heating rate of $2{ }^{\circ} \mathrm{C} / \mathrm{min}$, the gas

315 sweep made a difference, combusting a larger portion of the carbon and resulting in

316 ca. 32 atom \% of Sm, an increase of roughly a factor of 2 (Table 7). The morphology of the

317 fragments was comparable with what was discussed earlier, without any evident reduction in

318 fragment size compared to the oxidizing environment. This was then repeated with a faster

319 heating rate of $10^{\circ} \mathrm{C} / \mathrm{min}$ with depositions 3 and 4 , and a very similar result was seen. Again the

320 atom $\%$ of Sm was on the order of $32 \%$. This indicates that the heating zone indeed became

321 depleted, leaving a portion of organic substituents uncombusted. By adding an air sweep, the

322 supply of $\mathrm{O}_{2}$ to the combustion reaction is maintained throughout the entirety of the firing. It was

323 decided that depositions $1-4$ could be refired up to the higher temperature of $700{ }^{\circ} \mathrm{C}$ as there was

324 no observable change in morphology or definitive change in compositions at the lower

325 temperature of $125^{\circ} \mathrm{C}$. 
Table 7

327 Deposition thickness, size, and composition before and after firing to $125^{\circ} \mathrm{C}$, holding, and continuing up to $700{ }^{\circ} \mathrm{C}$ and holding in 328 air gas sweep.

\begin{tabular}{|c|c|c|c|c|c|c|c|c|c|c|}
\hline \multirow{2}{*}{ ID } & & \multirow{2}{*}{$\begin{array}{l}\text { Ramp Rate } \\
\left({ }^{\circ} \mathrm{C} / \mathrm{min}\right)\end{array}$} & \multirow{2}{*}{$\begin{array}{c}\text { Thickness } \\
(\mu \mathrm{m})\end{array}$} & \multirow{2}{*}{$\begin{array}{l}\text { Area } \\
\left(\mu \mathrm{m}^{2}\right)\end{array}$} & \multicolumn{2}{|c|}{ Diameter $(\mu \mathrm{m})$} & \multirow{2}{*}{$\begin{array}{c}\% \mathrm{Sm} \\
\text { (atom) }\end{array}$} & \multirow{2}{*}{$\begin{array}{c}\% \mathrm{O} \\
\text { (atom) }\end{array}$} & \multirow{2}{*}{$\begin{array}{c}\% \mathrm{C} \\
\text { (atom) }\end{array}$} & \multirow{2}{*}{$\begin{array}{c}\% \mathrm{Pt} \\
\text { (atom) }\end{array}$} \\
\hline & & & & & Range & Mean & & & & \\
\hline \multirow[t]{2}{*}{1} & Prefired & 2 & $5-10$ & $32-2256$ & $6-54$ & $27 \pm 14$ & 15 & 38 & 46 & 2 \\
\hline & Fired & & $2-8$ & $20-1523$ & $5-44$ & $14 \pm 9$ & 32 & 35 & 28 & 4 \\
\hline \multirow[t]{2}{*}{3} & Prefired & 2 & $3-9$ & $24-7666$ & $5-99$ & $34 \pm 21$ & 15 & 38 & 44 & 2 \\
\hline & Fired & & $2-7$ & $20-1554$ & $5-44$ & $15 \pm 10$ & 32 & 36 & 28 & 4 \\
\hline \multirow[t]{2}{*}{2} & Prefired & 10 & $4-8$ & $29-4810$ & $6-78$ & $31 \pm 18$ & 15 & 39 & 44 & 2 \\
\hline & Fired & & $3-8$ & $20-1006$ & $5-36$ & $15 \pm 7$ & 32 & 36 & 29 & 4 \\
\hline \multirow[t]{2}{*}{4} & Prefired & 10 & $4-7$ & $21-1052$ & $5-37$ & $19 \pm 9$ & 15 & 38 & 45 & 2 \\
\hline & Fired & & $2-7$ & $20-729$ & $5-30$ & $12 \pm 6$ & 32 & 35 & 29 & 4 \\
\hline
\end{tabular}

330 Changing to a reducing atmosphere, again using a $96 \% \mathrm{He} 4 \% \mathrm{H}_{2}$ gas mixture, and keeping the 331 same firing pattern, at heating rates of 2 and $10{ }^{\circ} \mathrm{C} / \mathrm{min}$ (Table 8) seems to produce slightly

332 poorer results compared to the oxidizing environment. When compared to the heating rate of

$3330.5^{\circ} \mathrm{C} / \mathrm{min}$ up to $700{ }^{\circ} \mathrm{C}$ without holding at $125^{\circ} \mathrm{C}$, it can be seen that the faster rates of heating

334 ( 2 and $10^{\circ} \mathrm{C} / \mathrm{min}$ ) were less effective at increasing the relative amount of $\mathrm{Sm}$ and driving off the

$335 \mathrm{C}$, only increasing the Sm atom \% by a factor of 1.9 .

Table 8

337 Deposition thickness, size, and composition before and after firing to $125{ }^{\circ} \mathrm{C}$, holding, and continuing up to $700{ }^{\circ} \mathrm{C}$ and holding in 338 a $96 \% \mathrm{He} 4 \% \mathrm{H}_{2}$ gas sweep.

\begin{tabular}{ccccccccccc}
\hline ID & & $\begin{array}{c}\text { Ramp Rate } \\
\left({ }^{\circ} \mathrm{C} / \mathrm{min}\right)\end{array}$ & $\begin{array}{c}\text { Thickness } \\
(\mu \mathrm{m})\end{array}$ & $\begin{array}{c}\text { Area } \\
\left(\mu \mathrm{m}^{2}\right)\end{array}$ & $\begin{array}{c}\text { Diameter }(\mu \mathrm{m}) \\
\text { Range }\end{array}$ & $\begin{array}{c}\text { \% } \mathrm{Sm} \\
(\text { atom })\end{array}$ & $\begin{array}{c}\% \mathrm{O} \\
(\text { atom })\end{array}$ & $\begin{array}{c}\% \mathrm{C} \\
(\text { atom })\end{array}$ & $\begin{array}{c}\% \mathrm{Pt} \\
(\text { atom })\end{array}$ \\
\hline \multirow{2}{*}{13} & Unfired & 2 & $4-10$ & $20-5576$ & $5-84$ & $28 \pm 18$ & 18 & 33 & 47 & 2 \\
& Fired & & $3-8$ & $20-1006$ & $5-59$ & $19 \pm 12$ & 32 & 40 & 25 & 3 \\
\multirow{2}{*}{14} & Unfired & 2 & $4-11$ & $20-3031$ & $5-62$ & $15 \pm 11$ & 16 & 34 & 48 & 2 \\
& Fired & & $2-7$ & $20-829$ & $5-32$ & $10 \pm 5$ & 31 & 40 & 24 & 5 \\
15 & Unfired & 10 & $5-11$ & $20-3207$ & $5-64$ & $29 \pm 15$ & 16 & 30 & 52 & 2 \\
& Fired & & $3-9$ & $21-1132$ & $5-38$ & $20 \pm 9$ & 31 & 35 & 30 & 4 \\
16 & Unfired & \multirow{2}{*}{10} & $4-11$ & $20-5955$ & $5-87$ & $23 \pm 18$ & 17 & 33 & 49 & 2 \\
& Fired & & $3-7$ & $21-1572$ & $5-45$ & $14 \pm 9$ & 30 & 37 & 29 & 4 \\
\hline
\end{tabular}

340 The deposited Sm was studied using XPS to better understand the chemical composition of the

341 Sm before and after firing. Measurements were performed on a plate prior to firing and a plate

342 fired with the same firing pattern as deposition 3. The acquired XPS spectra in the C 1s, O 1s, 
343 and Sm 3d regions for Sm deposition before and after firing are shown in Figs. 4 and 5. The

344 deposits were etched with argon after acquiring initial spectra to determine differences in

345 material as a function of thickness. The XPS spectra in the C 1s region for the unfired plate,

346 Fig. 4, shows a significant amount of carbonate-type carbon, and the $\mathrm{O} 1 \mathrm{~s}$ region shows a

347 significant amount of oxygen to carbon bonding, indicating the presence of acetate as a part of

348 the deposition. The presence of electrolyte species has been observed in similar by Vascon et al.

349 [16], as well. As summarized in Table 9, the chemical composition was calculated to be

$350 \mathrm{Sm}_{2} \mathrm{O}_{3} \cdot 2.5 \mathrm{C}_{2} \mathrm{H}_{3} \mathrm{O}_{2}{ }^{-}$on the surface and $\mathrm{Sm}_{2} \mathrm{O}_{3} \cdot 0.5 \mathrm{C}_{2} \mathrm{H}_{3} \mathrm{O}_{2}{ }^{-}$on the interior of the deposition. The

351 XPS spectra of the fired plate, Fig. 5, show relatively little amount of carbonate-type carbon and

352 oxygen-to-carbon-type bonding. This is especially true beneath the surface of the deposit, as

353 evidenced by looking at the etched spectra of the fired plate. From this, it is assumed that the

354 carbon signal is coming from $\mathrm{CO}_{2}$ sorbed to the surface of the deposition, resulting in a

355 calculated chemical composition of $\mathrm{Sm}_{2} \mathrm{O}_{3} \cdot 4.5 \mathrm{CO}_{2}$ on the surface and $\mathrm{Sm}_{2} \mathrm{O}_{3} \bullet 0.8 \mathrm{CO}_{2}$ on the

356 interior of the deposition. The excess of $\mathrm{O}$ seen in the post-fired etched sample is believed to be

357 due to oxide formation of the SS plate from the firing process. It can be inferred that acetate

358 makes up a large part of the Sm deposition, as indicated by the EDS data, and that the firing

359 process decomposed the deposited acetate, leaving only $\mathrm{Sm}_{2} \mathrm{O}_{3}$. It is interesting to note that the

360 atomic percentages calculated using the XPS data show a significant reduction of carbon present.

361 In addition, the carbon appears to be mainly present at the surface, particularly in the case of the

362 fired sample, as seen in comparing the before and after etching analysis. 

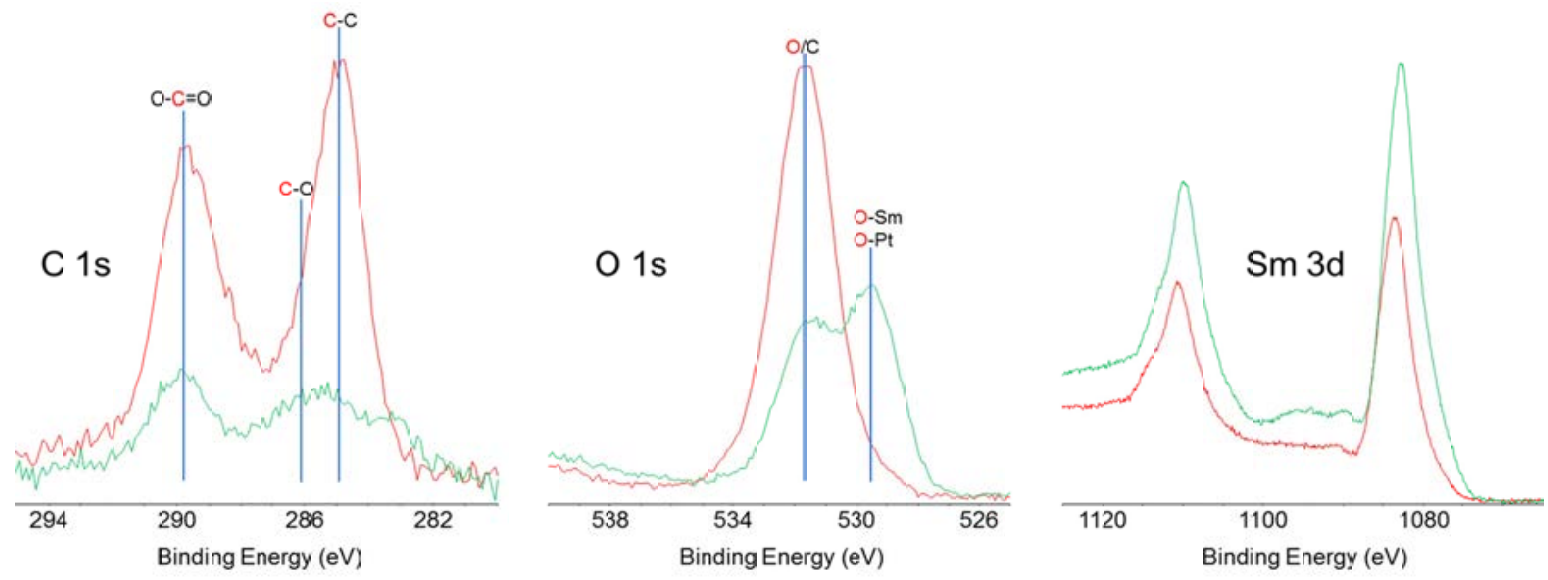

Fig. 4. XPS spectra of the Sm deposition before firing, collected prior to (red) and post (blue) etching with argon. Regions shown are the $\mathrm{C} 1 \mathrm{~s}, \mathrm{O} 1 \mathrm{~s}$, and $\mathrm{Sm} 3 \mathrm{~d}$ regions.
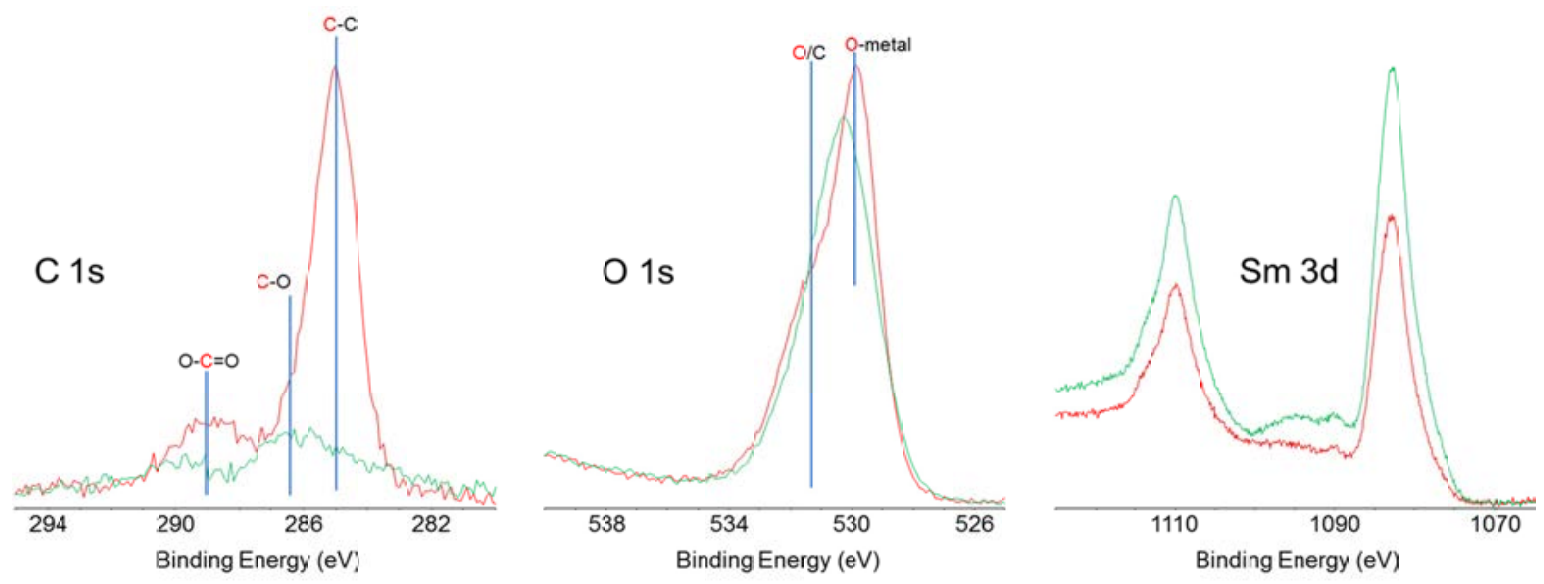

Fig. 5. XPS spectra of the Sm deposition after firing, collected prior to (red) and post (blue) etching with argon. Regions shown are the $\mathrm{C} 1 \mathrm{~s}, \mathrm{O} 1 \mathrm{~s}$, and $\mathrm{Sm} 3 \mathrm{~d}$ regions.

Table 9

Composition of an unfired and fired plate, pre- and post-etching, as observed by XPS.

\begin{tabular}{ccccc}
\hline \multirow{2}{*}{ Unfired } & $\begin{array}{c}\mathrm{Sm} \\
(\mathrm{mol})\end{array}$ & $\begin{array}{c}\mathrm{O} \\
(\mathrm{mol})\end{array}$ & $\begin{array}{c}\mathrm{C} \\
(\mathrm{mol})\end{array}$ \\
\hline \multirow{3}{*}{ Fired } & Pre-Etching & 2.0 & 8.2 & 5.2 \\
& Post-Etching & 2.0 & 3.9 & 1.0 \\
& Pre-Etching & 2.0 & 11 & 4.5 \\
& Post-Etching & 2.0 & 6.1 & 0.8 \\
\hline
\end{tabular}

*mole ratios set so $\mathrm{Sm}=2$

\section{Conclusion}


377 A series of Sm electroplated depositions were performed, with the yields predominately above

$37880 \%$. Firing to $125{ }^{\circ} \mathrm{C}$ in either air or a $96 \% \mathrm{He} 4 \% \mathrm{H}_{2}$ gas mixture did not have a noticeable

379 impact on the fragment size, thickness, morphology, or chemical composition. Increasing the

380 temperature to $700{ }^{\circ} \mathrm{C}$ did alter the depositions, reducing the size of the fragments, increasing the

381 relative composition of $\mathrm{Sm}$, and decreasing the relative composition of $\mathrm{C}$. The reducing

382 atmosphere was not as effective at removing the carbon content. Changing to a two-step firing to

383 remove the water at $125^{\circ} \mathrm{C}$ and then heating to $700{ }^{\circ} \mathrm{C}$ to burn off the organics, while varying the

384 heating rate from 0.5 to 2 to $10^{\circ} \mathrm{C} / \mathrm{min}$, showed that $10^{\circ} \mathrm{C} / \mathrm{min}$ was sufficiently slow to prevent

385 disruption of the deposition morphology during both the drying and combustion stages of the

386 firing. It was shown that a sweep gas is needed to enhance the removal of any organic

387 substituents, and an oxidizing environment to combust the organics is more advantageous than a

388 reducing one. It was also shown that acetate deposits along with the Sm and both decomposed,

389 leaving $\mathrm{Sm}_{2} \mathrm{O}_{3}$ after the firing process.

\section{Acknowledgements}

These authors gratefully acknowledge David Glasgow and the other NAA laboratory staff at the HFIR for their help in sample irradiation and data collection. We also gratefully

394 acknowledge Harry Mayer III at the HTML for performing the XPS experiments and data

395 collection. This research is supported by the U.S. Department of Energy, Office of Nuclear

396 Physics, Isotope Development and Production for Research and Applications Program. This

397 manuscript has been authored by UT-Battelle, LLC under Contract No. DE-AC05-00OR22725

398 with the U.S. Department of Energy. The United States Government retains and the publisher, by 399 accepting the article for publication, acknowledges that the United States Government retains a 
non-exclusive, paid-up, irrevocable, world-wide license to publish or reproduce the published

401 form of this manuscript, or allow others to do so, for United States Government purposes. The

402 Department of Energy will provide public access to these results of federally sponsored research

403 in accordance with the DOE Public Access Plan (http://energy.gov/downloads/doe-public-

404 access-plan).

405

\section{References}

[1] J. Runke, C.E. Düllmann, K. Eberhardt, P.A. Ellison, K.E. Gregorich, S. Hofmann, E. Jäger, B. Kindler, J. V. Kratz, J. Krier, B. Lommel, C. Mokry, H. Nitsche, J.B. Roberto, K.P. Rykaczewski, M. Schädel, P. Thörle-Pospiech, N. Trautmann, A. Yakushev, Preparation of actinide targets for the synthesis of the heaviest elements, J. Radioanal. Nucl. Chem. 299 (2014) 1081-1084. doi:10.1007/s10967-013-2616-6. Quantitative molecular plating of large-area 242Pu targets with improved layer properties, Appl. Radiat. Isot. 95 (2015) 36-43. doi:10.1016/j.apradiso.2014.10.002.

\section{[3] A. Vascon, C.E. Düllmann, K. Eberhardt, B. Kindler, B. Lommel, J. Runke, Toward} large-area targets for "TRAKULA," Nucl. Instruments Methods Phys. Res. Sect. A Accel. Spectrometers, Detect. Assoc. Equip. 655 (2011) 72-79. doi:10.1016/j.nima.2011.06.024.

[4] D. Leroy, L. Martinot, P. Mignonsin, B. Lambert, C. Jérôme, R. Jérôme, Immobilization of actinide ions in thin layers of polypyrrole/polyacrylamidoglycolic acid (PPy/PAGA) composite. Application to the preparation of alpha spectrometry sources, Radiochim. Acta. 90 (2002) 279-284. doi:10.1524/ract.2002.90.5_2002.279.

[5] S.K. Hanson, A.H. Mueller, W.J. Oldham Jr., Kläui Ligand Thin Films for Rapid Plutonium Analysis by Alpha Spectrometry, Anal. Chem. 86 (2014) 1153-1159. doi:10.1021/ac402997e.

[6] G. Bigazzi, J.C. Hadler N., P.J. Iunes, M. Oddone, S.R. Paulo, A. Zúñiga G., Absolute thermal neutron fluence determination by thin film of natural uranium, Nucl. Instruments Methods Phys. Res. Sect. A Accel. Spectrometers, Detect. Assoc. Equip. 352 (1995) 588591. doi:10.1016/0168-9002(95)90010-1.

[7] S. Guedes, R. Jonckheere, P.J. Iunes, J.C. Hadler, Projected-length distributions of fissionfragment tracks from $\mathrm{U}$ and Th thin film sources in muscovite, Nucl. Instruments Methods Phys. Res. Sect. B Beam Interact. with Mater. Atoms. 266 (2008) 786-790. doi:10.1016/j.nimb.2008.01.014.

[8] J.D. Burns, S.M. Van Cleve, E.H. Smith, R.A. Boll, Californium purification and electrodeposition, J. Radioanal. Nucl. Chem. 305 (2015) 109-116. doi:10.1007/s10967014-3815-5. 
[9] R.A. Boll, S.M. Van Cleve, N.J. Sims, L.K. Felker, J.D. Burns, G.D. Owen, E.H. Smith, C.S. White, J.G. Ezold, Californium electrodepositions at Oak Ridge National Laboratory,

[10] J.D. Burns, R.A. Boll, Californium Recovery from Palladium Wire, Sep. Sci. Technol. 50 (2015) 2819-2822. doi:10.1080/01496395.2015.1085875.

[11] J.B. Roberto, C.W. Alexander, R.A. Boll, J.D. Burns, J.G. Ezold, L.K. Felker, S.L. Hogle, K.P. Rykaczewski, Actinide targets for the synthesis of super-heavy elements, Nucl. Phys. A. 944 (2015) 99-116. doi:10.1016/j.nuclphysa.2015.06.009.

[12] E. Browne, R.B. Firestone, Table of Radioactive Isotopes, 1st ed., Wiley, New York, 1986.

[13] M.N. Torrico, R.A. Boll, M. Matos, Electrodeposition of actinide compounds from an aqueous ammonium acetate matrix: Experimental development and optimization, Nucl. Instruments Methods Phys. Res. Sect. A Accel. Spectrometers, Detect. Assoc. Equip. 790 (2015) 64-69. doi:10.1016/j.nima.2015.03.056.

[14] K. Eberhardt, W. Brüchle, C.E. Düllmann, K.E. Gregorich, W. Hartmann, A. Hübner, E. Jäger, B. Kindler, J.V. Kratz, D. Liebe, B. Lommel, H.-J. Maier, M. Schädel, B. Schausten, E. Schimpf, A. Semchenkov, J. Steiner, J. Szerypo, P. Thörle, A. Türler, A. Yakushev, Preparation of targets for the gas-filled recoil separator TASCA by electrochemical deposition and design of the TASCA target wheel assembly, Nucl. Instruments Methods Phys. Res. Sect. A Accel. Spectrometers, Detect. Assoc. Equip. 590 (2008) 134-140. doi:10.1016/j.nima.2008.02.069.

[15] M. Paunovic, M. Schlesinger, Fundamentals of Electrochemical Deposition, 2nd ed., John Wiley \& Sons, Hoboken, New Jersey, 2006.

[16] A. Vascon, S. Santi, A.A. Isse, A. Kühnle, T. Reich, J. Drebert, K. Eberhardt, C.E. Düllmann, Smooth crack-free targets for nuclear applications produced by molecular plating, Nucl. Instruments Methods Phys. Res. Sect. A Accel. Spectrometers, Detect. Assoc. Equip. 714 (2013) 163-175. doi:10.1016/j.nima.2013.03.003. 